\title{
Ventricular fibrillation and Takotsubo cardiomyopathy triggered by media panic on COVID-19: A case report.
}

Dirk Habedank ${ }^{1}$, Roland Thieme ${ }^{1}$, Angelika Bublak ${ }^{1}$, Felix Heinemann ${ }^{1}$, Sebastian Spencker $^{1}$, and Iskandar Atmowihardjo ${ }^{1}$

${ }^{1}$ DRK Kliniken Berlin Kopenick

September 11, 2020

\begin{abstract}
We report a case of Takotsubo cardiomyopathy (TTC) induced by diffuse fear of the COVID-19 pandemia and aggravated to ventricular fibrillation. After succesfull resuscitation the patient developed temporarily a J-wave after event. Though potentially live threatening in the acute phase both J-wave and TTC are reversible with receding of edema.
\end{abstract}

\section{Hosted file}

TTC and Covid19 var 2.docx available at https://authorea.com/users/357770/articles/480599ventricular-fibrillation-and-takotsubo-cardiomyopathy-triggered-by-media-panic-on-covid19-a-case-report 

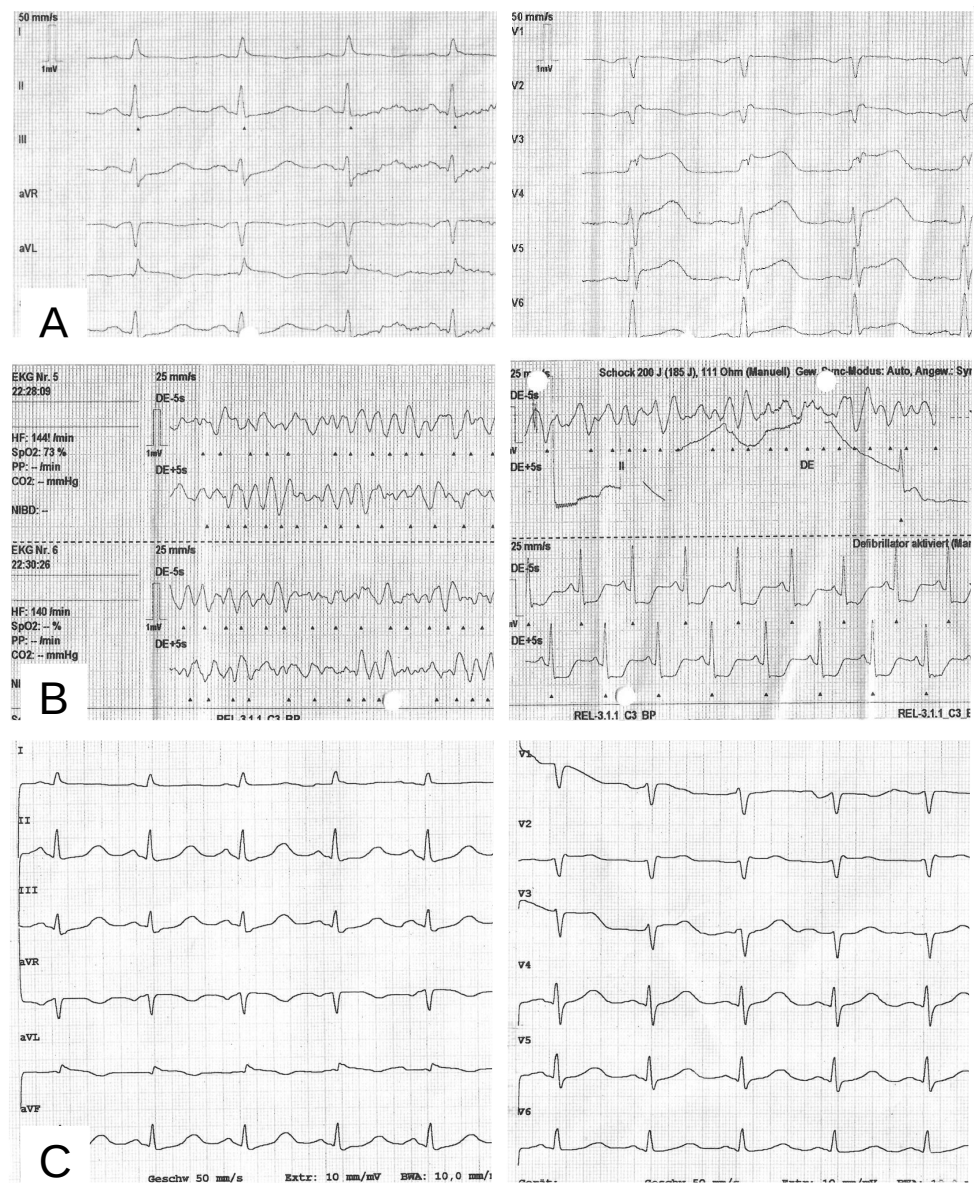

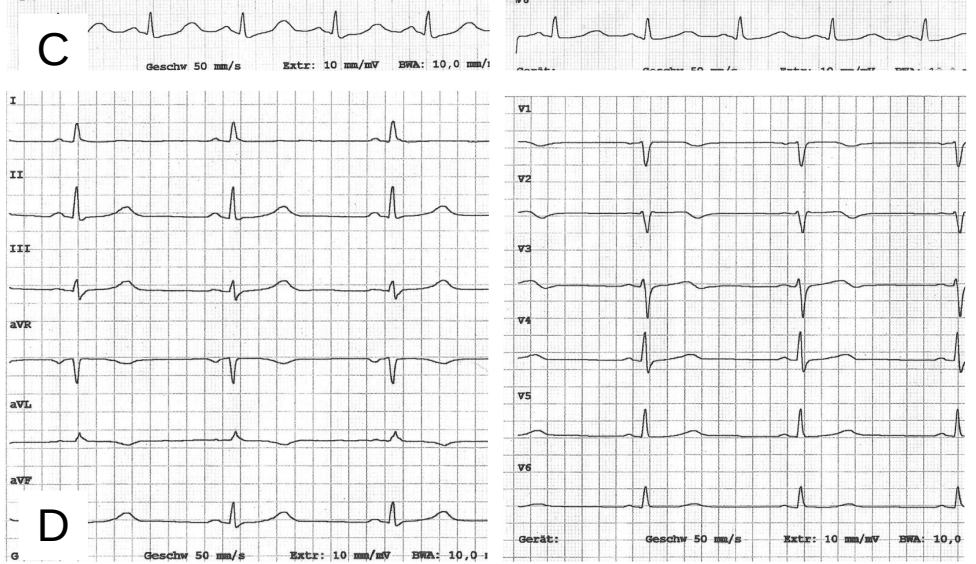

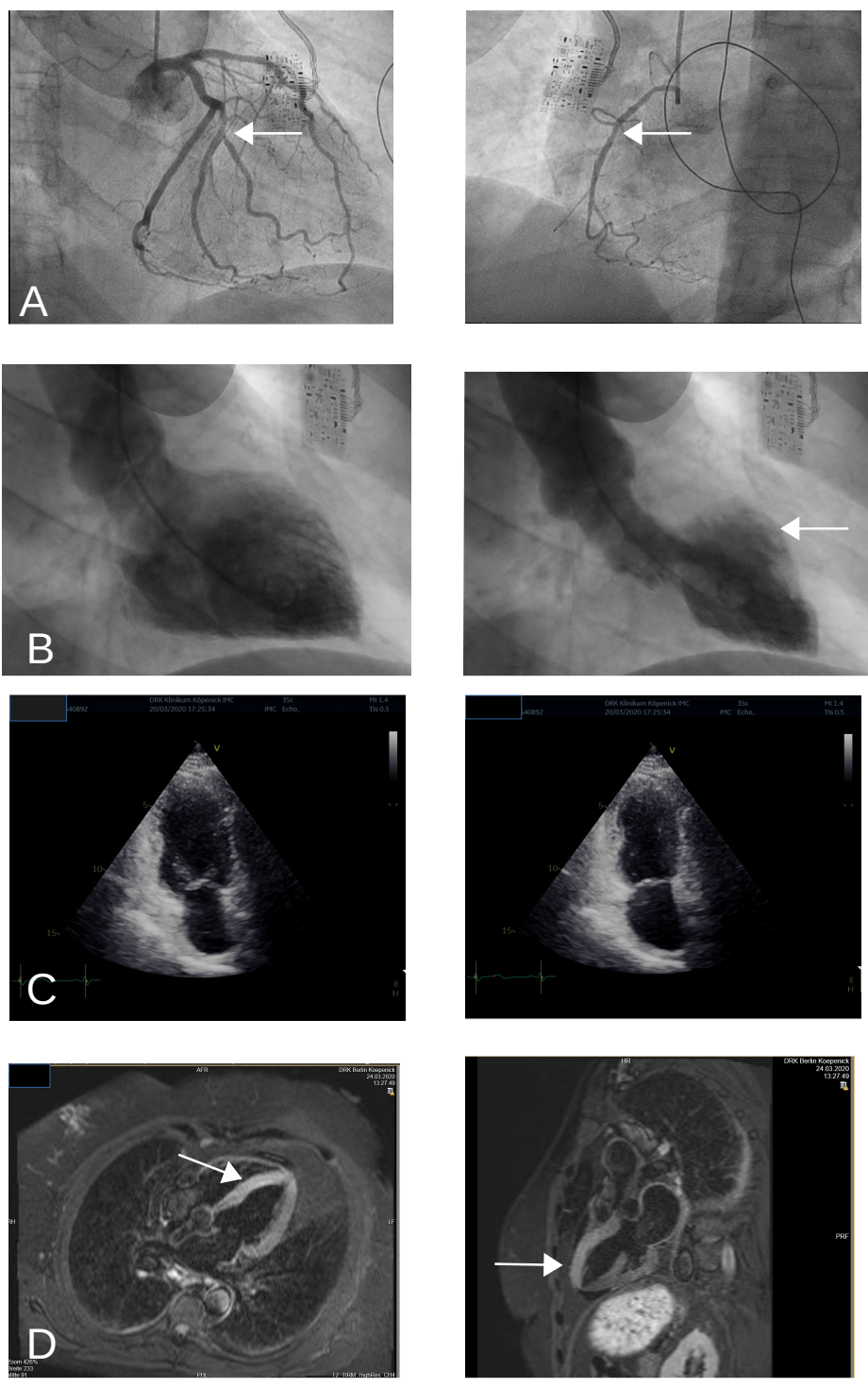